\title{
Is There an Urgent Need to Increase the Production of Doctors for Sri Lanka?
}

\author{
Karunathilake,I.M' ., Hanwella,D.V ${ }^{1}$., Gunathunga, $W^{1}$., Gunawardhana, $S^{1}$., Dharmaratne, $S^{1}$., \\ Ranasinghe, $C^{1}$., Witharana, $C^{1}$., Ubeysiri, $P^{1}$., Yeshan, $M^{1}$.
}

This is an evidence-based discussion on a specific question related to the current debates regarding medical education in Sri Lanka. The question in focus is "Is there an urgent need to increase the production of doctors for Sri Lanka?" This question would be discussed along a sequence of relevant sub questions.

\section{How many doctors do we have?}

This is a very basic question. However, given the complexity of the present situation in relation to the question, the answer is not very straight forward!

According to a very recent update, current number of active registrations in Sri Lanka Medical Council (SLMC) is 25600. These Medical graduates may work primarily in one of five different employment sectors i.e. (1) Ministry of Health, (2) university sector(3) private sector, (4) defense services (5) overseas. In 2006, De Silva et al, estimated that $70 \%$ of active registrants are employed in the Health Ministry, $3 \%$ in the universities, about $12 \%$ in the private sector, and the remaining $15 \%$ are overseas. ${ }^{1}$ Analysis of data during last 10 years (2006-2016) confirm that these percentages are still applicable. Employment within defense services was not considered here since it accounts only for less than one percent.

Calculations based on the above will provide us with an estimate of approximately 18,000 employed with the Ministry of Health, 2500-3000 working full time in the private sector, 700 to 800 in the universities. Number of those who have migrated or working overseas could be estimated as 4000-5000. Actual data obtained from different sources and estimates arrived at with more complex $\mathrm{HRH}$ modeling are in par with these figures( Ministry of Health Sri Lanka,2015; IHP Sri Lanka, 2015; De Silva,2017).

Based on the active registrations, current doctor: population ratio in Sri Lanka can be estimated as 1.04 per 1000 population. What does this mean? Does this ratio indicate anything about the adequacy or inadequacy of doctors to provide optimum care for the Sri Lankan population? This is a very difficult question to answer, because the optimum ratio would be dependent on factors that are as diverse as the health system and its ability to expand, economic state and its growth, disease patterns of the country and the social structure, etc. Below, we will draw from different sources of information to attempt a reasonable answer to this difficult question. One can only compare likes with likes.

\section{What can states/countries that are comparable to Sri Lanka tell us?}

Sri Lanka's doctor: population ratio is much higher than situations with comparable health indicators (e.g. Kerala), countries in the region with comparable GDP per capita and per capita expenditure on health (e.g. Indonesia) and countries with comparable rankings for health systems (e.g. Bangladesh) (WHO, 2006).

\footnotetext{
${ }^{1}$ Faculty of Medicine,

University of Colombo, Sri Lanka
}

Corresponding Author:

Professor Indika Karunathilake

Department of Medical Education, Faculty of Medicine, University of Colombo, Sri Lanka

E mail: karunathilake@hotmail.com

Is there a World Health Organization (WHO) recommended doctor-population ratio? 
WHO does not recommend a universal doctorpopulation ratio. What it suggests is to identify the effective need, based on the health system requirements and the capacity for the country to recruit doctors. Most importantly, WHO does not identify Sri Lanka as a country with critical shortage of doctors (WHO, 2000).

\section{Then, what would be a more pertinent issues?}

If doctor shortage is not a critical issue for Sri Lanka as a country, what causes crowded hospitals/clinics and long waiting lists for surgeries and investigations? Firstly, rather than shortage, maldistribution of doctors remains a serious concern in this issue. It is evident that the problem has not been corrected by rapid increase of the number of doctors joining the health sector during recent years. Conservative estimates suggest that the doctor: population ratio in the Colombo district is over $2.5 / 1000$, which is higher than the Singapore's ratio. This is in comparison with Nuwara Eliya district, which recorded the lowest value of 0.37 doctors per 1000 population in 2015(Ministry of Health Sri Lanka, 2015).

Secondly and more importantly, the slow expansion of the physical resources and infrastructure in the health care system and its uneven distribution seem to contribute to these service dynamics. This has indirectly supported the maldistribution of doctors, as they are invariably located to places where more service delivery is available. The reasons for slow health sector expansion could be due to country's' unfavorable GDP growth rate in the recent past and the curtailed allocation for healthcare which was maintaining around $2 \%$ of the GDP. This allocation is even less than in the regional countries like Maldives, Bhutan and Afghanistan.

\section{What may happen to the current doctor: population ratio in future?}

The average number of new registrations with SLMC is approximately 1500 /year during last five years. This number is expected to further increase due to the large number of students who are studying medicine in foreign universities (Estimated to be around 6000). Based on these trends, active registrations with SLMC will reach 35000 figure within next five years. This would give us a doctor: population ratio of 1.6 per 1000 for the Sri Lankan population projected for 2022.
Moreover, $70 \%$ of these new registrants can be expected to join the ministry of Health, according to the trend in past 10 years (de Silva, et al, 2008). If the government is to maintain absorbing $70 \%$ of the medical graduate output, the medical officer cadre in the Health Ministry will have to increase by about 1300 each year. This would mean that budgetary allocations for salaries of doctors and other carders, service improvements and infrastructure development need to go up annually. Given the current state of the economy and low budget allocations stagnating around $2 \%$ over the past years, this rapid expansion in the number of doctors does not appear sustainable.

Furthermore, if we assume the estimate for $15 \%$ migration rate to remain constant and ministry of health continues to absorb $70 \%$ new SLMC registrants, there will be over 250 graduates opting to join the private sector annually as full time practitioners. This is in addition to the government doctors who will continue to join private sector as part time practitioners. Currently this proportion is estimated to lie around $60 \%$. That means private sector capacity for employment has to increase by at least $20 \%$ each year based on the current estimate of 2500 doctors working in the private sector. However, when considering the trend of government salary revisions as well as the expansion of capacity and revenue in the private sector during the last 5 years, this may not be a likely scenario (IHP Sri Lanka, 2015).

With these projections and comparisons, it is possible to predict that our current health system, public and private included, will be saturated with medical doctors within next five years.

\section{What are the possible scenarios thereafter?}

Even if the private health sector grows significantly, if there is no guarantee of State sector employment, the proportion of medical graduates seeking employment overseas is bound to rise above the current level of $15 \%$.Doctors are more likely to start migrating to more lucrative countries that offer better remuneration when compared to private sector in Sri Lanka. The classic example would be that of India, a country with a doctor population ratio below Sri Lanka but has become the world's largest exporter of doctors. The argument that migrant doctors would bring foreign exchange to Sri Lanka is not necessarily true. As was seen 
through the 1970s exodus of graduates, except for some indirect family support and occasional small scale investments many would utilize their earnings in the country they reside in.

Having doctors in excess of a country's health system may have certain benefits such as doctors being compelled to maintain better efficiency and work ethics to retain employment and employers having a wider choice when recruiting doctors according to task requirement. However, there are concerns that excess numbers could lead to de-stabilization of the health system, through factors such as increase in internal and out migration, underutilization of skills and more commodification of health care. Health economists argue that the competition occurring due to excessive number of doctors may not bring down cost of care, due to the fact that market forces of healthcare are not mainly determined by consumer decision and choice. Underemployed physicians are a costly resource to maintain(WHO, 2000)

\section{Will health care be improved by only increasing the number of doctors?}

Absolutely not! Numbers are only part of the story. Increasing the number of doctors alone has never solved Human Resources in Health $(\mathrm{HRH})$ issues. In fact uncoordinated, unplanned expansion of medical education has worsened the situation as illustrated by many examples worldwide. For example, Malaysia, a country with much higher GDP per capita, higher ranked health system and higher budgeted allocation for health than Sri Lanka has reached a situation where the health system cannot absorb the increasing number of medical graduates and had to issue a moratorium on starting new medical schools or courses. We need to act before we reach such a situation.

The ultimate goal should be the improvement of the quality of health care. Patients expect better accessibility to health, acceptable cost, caring and skilled doctors and lesser waiting times. $\mathrm{HRH}$ means right persons in the right place in right numbers with right skills and attitudes. To achieve these there need to be improved quality of training, proper coordination between training and recruitment, career development, reward management, need-based deployment, better facilities, infrastructure and health system changes. This is where the government should focus on. These are the areas the intellects should be lobbying for policy changes.

\section{References:}

De Silva, Perera, N.R., Gunatunge, K.K.Y.W., Tantrigoda, R.S. (2008), How many doctors should Sri Lanka have?, Ceylon Medical Journal, 53, (3), pp.93-98.

Ministry of Health, Health Information Unit \& Management Development and Planning Unit. (2015) Human Resources Profile, Health Staff In position by 31December 2015, Ministry of Health, Sri Lanka.

<http://www.health.gov.lk/moh_final/english/publi c/elfinder/files/publications/HRMprofile2016.pdf $>$ [accessed on April 24, 2017].

IHP,Sri Lanka (2015) Private Health Sector Review 2012. August 2015 (Revised Edition)

$<$ http://www.ihp.lk/publications/docs/PHSR2012.p df $>$ [accessed on April 24, 2017].

De Silva, D., Personal communication, March 28, 2017.

WHO (2006) The World Health Report 2006: working together for health. Geneva: World Health Organization.

<http://www.who.int/whr/2006/whr06_en.pdf?ua= $1>$ [accessed on April 24, 2017].

WHO (2000) "Measuring overall health system performance for 191 countries".

<http://www. who.int/healthinfo/paper30.pdf>[acce ssed on April 24,2017].

Abel-Smith B., Leiserson, A. (1978), Poverty, development and health. Public health paper no. 69, Geneva, World Health Organization. 